\title{
A PROSPECTIVE STUDY OF CLINICAL PROFILE OF STROKE IN A TERTIARY CARE HOSPITAL
}

\section{CHACHU KURIAKOSE, NASEEM SHIFAFIYA M, NELTA S THARAKAN, SATTANATHAN K*, SAMBATH KUMAR R}

Department of Pharmacy Practice, J.K.K. Nattraja College of Pharmacy, Kumarapalayam, Tamil Nadu, India. Email: sattanathan.k@jkkn.org Received: 22 June 2016, Revised and Accepted: 31 August 2016

\section{ABSTRACT}

Objective: The objective of the work was to study the clinical profile of stroke in a tertiary care hospital.

Methods: A prospective observational study on stroke was carried out for a period of 6-month (May 2015 to 0ctober 2015). A total of 241 inpatients from Shri Preethi Hospital were incorporated in the study. The data were collected and evaluated by reviewing case files and patient interview.

Result and Conclusion: Out of 241 patients, an incidence of ischemic stroke was found to be higher. The occurrence of stroke steeply rises with age with male predominance. The burden of stroke tends to be more in rural, illiterate, and low socioeconomic status population. The study reveals risk factors such as sedentary lifestyle, previous and family history of stroke, underlying disease like hypertension, diabetes. The circadian pattern in onset showed a significant peak in morning ( $6 \mathrm{am}-12 \mathrm{pm})$ for Ischemic and afternoon (12 pm-6 pm) for hemorrhagic stroke. Topographic distribution of cerebral infract and hemorrhage was found to be in parietal lobe and periventricular white matter, respectively. Mostly prescribed medication for ischemic and hemorrhagic patients was antihypertensive and mannitol, respectively. The contraindication for thrombolytic therapy was found to be low economic status and average delay in time of presentation to hospital. The study highlights the need for aggressive management of traditional risk factors, need for extensive work up in patient to find etiologies and need for more active interventions in community for the prevention of stroke.

Keywords: Ischemic, Hemorrhagic, Circadian pattern, Antihypertensive.

(C) 2016 The Authors. Published by Innovare Academic Sciences Pvt Ltd. This is an open access article under the CC BY license (http://creativecommons. org/licenses/by/4. 0/) DOI: http://dx.doi.org/10.22159/ajpcr.2016.v9s3.13622

\section{INTRODUCTION}

According to the World Health Organization (WHO), stroke is a clinical syndrome characterized by rapidly developing clinical symptoms and/or signs of focal, and at times global (applied to patients in deep coma and those with subarachnoid hemorrhage), loss of cerebral function, with symptoms lasting more than 24 hrs or leading to death, with no apparent cause other than that of vascular origin (Hatano, 1976). Stroke was found to be the second leading cause of death and was predominant at age above 60 years, simultaneously the fifth leading cause of death among age group of 15-59 years old. The next two decades predictions suggest that there would be a tripling mortality rate in the Middle East, sub-Saharan Africa and Latin America [1,2]. According to WHO estimation, by 2050 nearly $80 \%$ of stroke cases may occur in low and middle-income countries like China and India [3]. Reliable mortality and morbidity estimate that in India stroke cases are limited due to incorrect death classification, uncertainty in identifying the causes of sudden death, multiple co-morbid diseases, and incomplete death certification.

Ischemic and hemorrhagic stroke accounts for about $87 \%$ and $13 \%$, respectively [4]. Ischemic stroke may be due to an obstruction within the blood vessel that supplies blood to the brain. Hemorrhagic stroke occurs due to the weakening of blood vessel which would rupture and bleed into the surrounding brain tissues. This blood would accumulate and compress the surrounding tissue [5-7].

Risk factors include non-modifiable factors (age, gender, race, family and previous history, low birth weight), potentially modifiable factors (excessive alcohol, hypercoagulability, drugs, oral contraceptive use, acute infection), and modifiable factors (smoking or tobacco use, obesity, residential area, diet) [8-10]. The American Heart Association/ American Stroke Association (AHA/ASA) guideline recommends neurological examination using the National Institute of Health Stroke Scale (NIHSS). The AHA/ASA recommends tissue plasminogen activator, antiplatelet (aspirin, clopidogrel), anticoagulants (heparin, warfarin), antihypertensives and lipid-lowering agents for the treatment if ischemic stroke whereas osmotherapy, neuromuscular relaxants, neuroprotection and neurorestoration therapy, reperfusion therapy and calcium channel blockers for hemorrhagic stroke [11-16]. Our study was helpful in determining the frequency and percentage of risk factors, clinical manifestations, severity assessment, and current prescription trends in stroke patients admitted to a tertiary care Hospital.

\section{METHODS}

A prospective observational study was conducted with the consent from Head of Department in Neurology of Shri Preethi Hospital, Erode. The study was approved by Institutional Ethics Committee.

The study was carried out for a period of 6-month from May 2015 to October 2015 in 241 stroke patients. The patient information was collected and analyzed by reviewing case files and patient interview. Patients diagnosed with Ischemic and hemorrhagic stroke with or without comorbid disease, age above 20 years and of both genders were included in the study. The demographic data such as age, gender, risk factors (lifestyle, diet, body mass index, educational and socioeconomic status, resident areas, previous and family history, co-morbid disease), onset of stroke, and neurological severity using NIHSS, contraindication of thrombolytic therapy were determined by patient interview whereas topographic distribution and prescribing trends were determined by reviewing case files.

\section{RESULTS}

The study revealed that, from a total of 241 patients, 227 patients were diagnosed with ischemic stroke and 14 patients were diagnosed with hemorrhagic stroke, the incidence of ischemic stroke (94\%) was found to be higher than that of hemorrhagic stroke $(6 \%)$. Cardioembolic stroke among ischemic patients was found to be $39 \%$. The occurrence of ischemic and hemorrhagic stroke steeply rises with age and ranged between 61 and 80 years (54\%) and 41 and 60 years (50\%), respectively. Table 1 shows the socio-demographic characteristics of stroke. A first-degree family history of cardiovascular disease was reported by 125 patients (55\%) in Ischemic stroke and 9 patients 
(64\%) in hemorrhagic stroke. While accounting for the hypertension stages, most of the patients were presented with stage II Hypertension. Smoking, alcoholism, betel nut use, diet, drinking habits, hypertension, and diabetes mellitus were the most common risk factor among stroke (Tables 1 and 2). Among Ischemic stroke, onset of circadian pattern shows a significant peak in 111 patients (49\%) in morning (6 am-12 pm) followed by 55 patients (24\%) in afternoon. Similarly, 6 patients $(43 \%)$ in afternoon (12pm-6 pm) followed by 4 patients $(29 \%)$ in the late evening ( $6 \mathrm{pm}-12 \mathrm{am})$ showed a significant peak in hemorrhagic stroke. The majority of patients (56\% of ischemic stroke and $64 \%$ of hemorrhagic stroke) were present with 3-4 clinical manifestation during admission. Most of the ischemic patients presented symptoms such as weakness of right side (42\%), slurred speech (40\%), giddiness (36\%), and weakness of left side (35\%). Similarly, a more number of hemorrhagic patients presented the symptoms such as vomiting (50\%), headache (43\%), and slurred speech (36\%). While considering the topographic distribution of cerebral infract, most commonly affected site was parietal lobe (35\%) followed by corona region $(26 \%)$, basal ganglia (19\%). Whereas while considering the topographic distribution of hemorrhage, most commonly affected site was periventricular white matter $(50 \%)$, basal ganglia (29\%). Neurological assessment of stroke severity was assessed using NIHSS. The majority of patients shows moderate to severe neurological deficit $38 \%$ for Ischemic stroke and $57 \%$ for hemorrhagic stroke). When considering drug utilization in ischemic stroke, commonly prescribed medications were antihypertensive followed by antiplatelets, lipid lowering agent, and nootropics (Table 3). At the same time commonly prescribed antihypertensive were amlodipine (42\%) followed by mannitol (37\%), furosemide $(36 \%)$. The drug utilization in hemorrhagic stroke was mannitol (57\%) followed by nimodipine and enalapril (50\%). The contraindication for thrombolytic therapy for ischemic stroke was found to be low economic status (195 patients) and average delay in time of presentation to hospital was more than 3 hours for 199 patients.

\section{DISCUSSION}

Among 241 patients presented with stroke, the incidence rate of Ischemic stroke was more than that of hemorrhagic stroke, this may be due higher prevalence of clinical factors such as advanced age, male gender, sedentary lifestyle, time of varying prevalence of risk factors, hypertension, obesity, family history of cardiovascular, and cerebrovascular disease. This finding is in contrast with the finding by Koton et al. [17] Cardioembolism was one of the major causes for ischemic stroke; this constellation might be explained by increasing age, sedentary lifestyle, and associated cardiovascular disorder [18].

A gender wise distribution of stroke shows a male predominance. The possible explanation may be increased risk factors in male such as cigarette smoking and alcohol consumption; in addition, there is no vascular protection of endogenous estrogens in male. Concurrent results were obtained in study conducted by Zhao et al. [19] During the time of admission, the patients of age group 61-80 years were predominant in the Ischemic group, whereas patients of age group 41-60 years were predominant in the hemorrhagic group. This may be due to the decreased physical activity and lower educational status among elderly when compared to young.

In the study conducted, patients had a previous and family history of stroke. The overall outcome of stroke incidence on the basis of previous history was attributed to the lack of proper treatment of risk factors, poor health care and reduced awareness among the patients [20].

Table 1: The socio-demographic characteristics of stroke

\begin{tabular}{llll}
\hline Variable & Category & $\begin{array}{l}\text { Frequency distribution among } \\
\text { ischemic stroke patients (n=227) (\%) }\end{array}$ & $\begin{array}{l}\text { Frequency distribution among } \\
\text { hemorrhagic stroke patients (n=14) (\%) }\end{array}$ \\
\hline Gender & Male & $153(67)$ & $9(64)$ \\
Food habits & Female & $76(33)$ & $5(36)$ \\
& Vegetarian & $76(34)$ & $6(43)$ \\
Drinking habits & Non vegetarian & $37(16)$ & $2(14)$ \\
& Mixed diet & $113(50)$ & $6(43)$ \\
& Coffee & $75(33)$ & $4(29)$ \\
BMI & Tea & $56(25)$ & $2(14)$ \\
& Mixed & $96(42)$ & $8(57)$ \\
& Underweight & $17(7)$ & $2(14)$ \\
Family history & Normal weight & $47(21)$ & $2(14)$ \\
\multirow{2}{*}{ Residential area } & Over weight & $72(32)$ & $4(29)$ \\
\multirow{2}{*}{ Educational status } & Obese & $84(40)$ & $6(43)$ \\
& With family history & $142(63)$ & $6(43)$ \\
& Without family history & $149(66)$ & $8(57)$ \\
& Rural & $78(34)$ & $12(86)$ \\
Occupational status & Urban & $125(55)$ & $2(14)$ \\
& Illiterate & $84(37)$ & $8(57)$ \\
& Schooling & $18(8)$ & $2(14)$ \\
& Graduate & $43(55)$ & $3(21)$ \\
& Business & $76(33)$ & $5(36)$ \\
& Daily worker & $55(24)$ & $4(29)$ \\
& Agriculture & $23(10)$ & - \\
& Sales and service & $30(13)$ & $2(14)$ \\
\hline
\end{tabular}

Table 2: Common risk factor for stroke

\begin{tabular}{|c|c|c|c|c|c|}
\hline \multirow[t]{2}{*}{ Variable } & \multirow[t]{2}{*}{ Category } & \multicolumn{2}{|c|}{$\begin{array}{l}\text { Frequency distribution among ischemic } \\
\text { stroke patients }(n=227)\end{array}$} & \multicolumn{2}{|c|}{$\begin{array}{l}\text { Frequency distribution among } \\
\text { hemorrhagic stroke patients }(n=14)\end{array}$} \\
\hline & & Male (\%) & Female (\%) & Male (\%) & Female (\%) \\
\hline \multirow[t]{3}{*}{ Social habits } & Smoking & $113(73)$ & - & $7(78)$ & - \\
\hline & Alcoholic & $94(61)$ & - & $3(33)$ & - \\
\hline & Betal nut user & $88(58)$ & $43(43)$ & $5(56)$ & $2(40)$ \\
\hline
\end{tabular}


Table 3: Prescribing pattern in stroke

\begin{tabular}{llll}
\hline Category & Drugs & $\begin{array}{l}\text { Frequency distribution among } \\
\text { Ischemic stroke patients (n=227) (\%) }\end{array}$ & $\begin{array}{l}\text { Frequency distribution among } \\
\text { hemorrhagic stroke patients (n=14) (\%) }\end{array}$ \\
\hline Antiplatelets & Aspirin & $132(58)$ & - \\
& Clopdiogrel & $123(54)$ & - \\
& Aspirin+dypiridamole & $6(3)$ & - \\
Anticoagulants & Aspirin+clopidogrel & $25(1)$ & - \\
& Heparin & $103(45)$ & - \\
Nootropics & Enoxaparin & $7(3)$ & - \\
& Citicoline & $116(51)$ & - \\
Lipid lowering agent & Methylcobalamine & $98(43)$ & - \\
Beta blockers & Piracetam & $24(11)$ & - \\
& Atorvastatin & $166(73)$ & $6(43)$ \\
& Atenolol & $29(13)$ & - \\
Calcium channel blocker & Bisoprolol & $6(3)$ & $2(14)$ \\
& Carvidilol & - & $1(7)$ \\
Alpha blockers & Aetoprolol & - & $6(43)$ \\
ACE inhibitors & Nifedipine & $96(42)$ & $4(29)$ \\
Osmotic diuretics & Nimodipine & - & $7(50)$ \\
Loop diuretics & Prazosin & $5(2)$ & - \\
ARB & Clonidine & $5(2)$ & $4(29)$ \\
Potassium sparing diuretics & Enalapril & $51(22)$ & $7(50)$ \\
& Mannitol & $83(37)$ & $8(57)$ \\
& Furosemide & $82(36)$ & $3(21)$ \\
& Aldactone & $20(9)$ & - \\
\hline
\end{tabular}

First degree family history of cardiovascular disorder had a moderate familial risk on Stroke. This could be explained by hereditary relationship [21]. The burden of stroke tends to be more in rural population than that of urban population which may be attributed to reduced awareness in rural areas along with the consequent lack of monitoring which may probably lead to under-reporting or underdiagnosis by general physicians [22].

The available data show that the majority of patients were illiterate and daily workers. Illiteracy and low socioeconomic status are highrisk population with increased work load and stress, on the other hand, moderate and highly educated population along with high socioeconomic status have improved medication adherence with proper utilization of health-care system and health behavior counseling, this reduces recurrent stroke [23]. Body mass index $>25 \mathrm{~kg} / \mathrm{m}^{2}$ had a strong association with the occurrence of stroke. Compared to normal weight patients, obese and overweight patients tend to develop a high risk for stroke. This may be associated with increased risk factors, obstructive sleep apnea, insulin resistance, pro-thrombotic state (higher presence of thrombotic cofactor), and sympathetic nervous system activation status which are related to thrombotic adverse events thereby reducing the functional outcome and may result in catabolic imbalance. At the same time, immobilization in obese patients can impair the post Stroke recovery. The suggestive evidence was found in study conducted by Wang et al. [24]

Hypertension is one of the risk factors in ischemic and hemorrhagic stroke. Hypertension results in hyaline degeneration of smaller cerebral vessels, atherosclerosis in larger cerebral vessel, alteration of cerebral perfusion, imbalance in the cerebrovascular autoregulation, hypertrophy and remodeling of cerebral vessels which may be attributed to illiteracy, limited awareness of hypertension, food habits and sedentary lifestyle [25]. The confounding variables such as current smoking, alcoholics, and betel nut use are independently associated with stroke risk. The majority of smokers developed stroke due to the reason that smoking may predispose to cerebral thrombosis possibly by causing an imbalance between brain vascular coagulation and abnormal Fibrinolysis at the same time it might alter the function of blood brain barrier and disrupt normal endothelial cell function [26]. The plausible relation between alcoholism and risk factor of stroke is more susceptible to triggering effect which causes cardiogenic brain embolism and hypertension thereby increases the risk of Ischemic stroke. At the same time, it may be antithrombotic and atherogenic, leading to increased high-density lipoprotein, decreased platelet aggregation, clot formation, and increased fibrinolysis thereby increasing risk of hemorrhagic stroke [27]. Betel nut user developed stroke due to the reason that arecoline, content of betel nut, induces COX-2 up-regulation, which may result in cerebrovascular abnormalities [28].

The relation between risk of stroke and diet may be an increased daily total fat intake, especially above $65 \mathrm{~g}$, significantly increases risk of stroke, whereas vegetarian foods have low saturated fat and are high in unsaturated fat [29]. Habitual coffee consumption may raise the blood pressure [30]. Our results deviate from study conducted by Larsson et al. [31] and Zhang et al. [32]

The Circadian pattern in onset of ischemic and hemorrhagic stroke showed a significant peak in morning (6 am-12 pm) and afternoon (12 pm-6 pm), respectively. The could be correlated to biological factors such as blood pressure (with physiological nocturnal decrease and morning increase), hemostatic balance (with increased platelet aggregability, increased level of hematocrit with hyperviscosity of blood in morning hypercoagulability, hypofibrinolysis) autonomic systemic activity (with activation of sympathetic nervous system after wake up movement with consequence on vascular tone, blood pressure, heart rate). The endogenous factors also depend partially by the day-night cycle of the physical activity and assumption of the up-right posture (as exogenous factors) associated with awaking movement[33].

The prescribing trends found in Ischemic stroke patients were antihypertensive (amlodipine, mannitol, furosemide, and enalapril) followed by antiplatelets, lipid lowering agent, and nootropics. These results show remarkable coincidence with study conducted by Geetha et al. [34] and White et al. [35]. While considering drug utilization in hemorrhagic stroke patients, commonly prescribed drugs were mannitol followed by Preethi [36].

According to AHA/ASA guidelines, the prescribing trends for ischemic stroke were antiplatelet therapy like aspirin, clopidogrel followed by antihypertensive like angiotensin converting enzyme and diuretics. And for hemorrhagic stroke was found to be calcium channel blocker 
like nimodipine followed by antihypertensive like labetalol, esmolol, enalapril. The prescription was found to be rational [37].

\section{CONCLUSION}

The study was helpful in determining the incidence, risk factors, clinical manifestation, circadian pattern in onset, and prescribing trends among Stroke patients admitted to a tertiary care hospital. The incidence of ischemic stroke was found to be higher. The study reveals that there exists a strong correlation between age and gender in developing stroke. Sedentary lifestyle, diet, obesity, residential area, previous and family history of stroke, hypertension and diabetes may be contributor to stroke risk. Manual tracing methods like CT scan, MRI remain the standard technique for determining topographic distribution and delineating damaged brain regions. The results confirm the presence of circadian variation among stroke, predominately in the early morning and afternoon hours. The drug utilization review was based on AHA/ASA, and most of the prescriptions were found to be rational. The study provides a framework for continuous evaluation of prescription pattern among stroke patients.

This study conducted to create awareness among public, thereby providing information on symptoms, risk, and treatment. The study also paves a way to change the behavioral pattern and prevent early recurrent stroke. Our study helps to determine adherence on the standard clinical guidelines for management of stroke and as evidence for future research

Limitation of the study includes relatively smaller sample size, the study was attributed to a single hospital, information on menopausal status, and use of hormone replacement therapy were not available. Another limiting factor could be non-responding of smoking among females who may tend to hide this habit due to socio-cultural reasons. Relation between second-hand smokers and past smokers as a risk for stroke was not studied. Prescribing trends in combination therapy were not analyzed.

\section{REFERENCES}

1. Stroke, World Heart Federation. The global burden of stroke. Available from: http://www.worldheart federation.org/cardiovascular-health stroke. [Last updated on 2015 Jan 02, Last assessed on 2015 Jul 01].

2. Thrift AG, Cadilhac DA, Thayabaranathan T, Howard G, Howard VJ, Rothwell PM, et al. Global stroke statistics. Int J Stroke 2014;9(1):6-18.

3. Pandian JD, Sudhan P. Stroke epidemiology and stroke care services in India. J Stroke 2013;15(3):128-34.

4. Anthony S, Kasper L, Dan L, Braunwald E. Harrison's Principles of Internal Medicine. $17^{\text {th }}$ ed. United States of America, NY: McGrawHill; 2012.

5. Gary D, Stephen J. Pathophysiology of Disease an introduction to Clinical Medicine. $7^{\text {th }}$ ed. New York, NY: McGraw-Hill; 2014.

6. Glen C, Zhi L, Boryana S, Bradley P, Xinhua Z. Hemorrhagic transformation after ischemic stroke in animals and humans. J Cereb Blood Flow Metab 2014;34(2):185-99.

7. Subha PP, Pillai Geethakumari SM, Athira M, Nujum ZT. Pattern and risk factors of stroke in the young among stroke patients admitted in medical college hospital, Thiruvananthapuram. Ann Indian Acad Neurol 2015;18(1):20-3.

8. Jauch EC, Saver JL, Adams HP Jr, Bruno A, Connors JJ, Demaerschalk BM, et al. Guidelines for the early management of patients with acute ischemic stroke: A guideline for healthcare professionals from the American heart association/American stroke association. Stroke 2013;44(3):870-947.

9. Marinigh R, Lip GY, Fiotti N, Giansante C, Lane DA. Age as a risk factor for stroke in atrial fibrillation patients: Implications for thromboprophylaxis. J Am Coll Cardiol 2010;56(11):827-37.

10. Haast RA, Gustafson DR, Kiliaan AJ. Sex differences in stroke. J Cereb Blood Flow Metab 2012;32(12):2100-7.

11. Lisabeth L, Bushnell C. Stroke risk in women: The role of menopause and hormone therapy. Lancet Neurol 2012;11(1):82-91.

12. James AH, Bushnell CD, Jamison MG, Myers ER. Incidence and risk factors for stroke in pregnancy and the puerperium. Obstet Gynecol 2005;106(3):509-16.
13. American stroke association. Understanding stroke risk. Available form: http://www.strokeassociation.org. [Last accessed on 2015 Jul 01].

14. Eriksson JG, Forsén T, Tuomilehto J, Osmond C, Barker DJ. Early growth, adult income, and risk of stroke. Stroke 2000;31(4):869-74.

15. Lee JH, Lee JY, Ahn SH, Jang MU, Oh MS, Kim CH, et al. Smoking is Not a Good Prognostic Factor following First-Ever Acute Ischemic Stroke. J Stroke 2015;17(2):177-91.

16. Leira EC, Hess DC, Torner JC, Adams HP Jr. Rural-urban differences in acute stroke management practices: A modifiable disparity. Arch Neurol 2008;65(7):887-91.

17. Koton S, Schneider AL, Rosamond WD, Shahar E, Sang Y, Gottesman RF, et al. Stroke incidence and mortality trends in US communities, 1987 to 2011. JAMA 2014;312(3):259-68.

18. Porcello Marrone LC, Farina Brunelli JP, Lutzky Saute R, Henrique Tomasi G, Cecchele Madeira B, Alves Martins W, et al. Cardioembolic sources in stroke patients in South of Brazil. Thrombosis 2014;2014:753780.

19. Zhao W, Katzmarzyk PT, Horswell R, Wang Y, Johnson J, Hu G. Sex differences in the risk of stroke and $\mathrm{HbA}(1 \mathrm{c})$ among diabetic patients. Diabetologia 2014;57(5):918-26.

20. Eapen RP, Parikh JH, Patel NT. A study of clinical profile and risk factors of cerebrovascular stroke. Guj Med J 2009;64(2):47-54.

21. Øygarden H, Fromm A, Sand KM, Eide GE, Thomassen L, Naess H, et al. Stroke patients' knowledge about cardiovascular family historythe Norwegian Stroke in the Young Study (NOR-SYS). BMC Neurol 2015;15:30.

22. Vasavilatha G, Krishna M, Kranthi P, Chandrasekar M. Study on role of risk factor cerebrovascular stroke. JEMDS 2015;4(6):914-24.

23. Kumar A, Prasad M, Kathuria P, Nair P, Pandit AK, Sahu JK, et al. Low socioeconomic status is an independent risk factor for ischemic stroke: A case-control study in North Indian population. Neuroepidemiology 2015;44(3):138-43.

24. Wang HJ, Si QJ, Shan ZL, Guo YT, Lin K, Zhao XN, et al. Effects of body mass index on risks for ischemic stroke, thromboembolism, and mortality in Chinese atrial fibrillation patients: A single-center experience. PLoS One 2015;10(4):e0123516.

25. Imano H, Kitamura A, Sato S, Kiyama M, Ohira T, Yamagishi K, et al. Trends for blood pressure and its contribution to stroke incidence in the middle-aged Japanese population: The Circulatory Risk in Communities Study (CIRCS). Stroke 2009;40(5):1571-7.

26. Khalid W. Clinical profile of stroke patients and the association of carotid intimamedia thickness at Al-Madinah, Saudi Arabia. Life Sci J 2015;12(3):1-6.

27. Indira Y, Muralidhar MV, Munisekhar K. Role of smoking and alcoholism in cerebrovascular Accidents. Int $\mathrm{J}$ Physiother Res 2014;2(3):530-6.

28. Mateen F, Carone M, Alam N, Streatfield K. A population based case control study of 1250 stroke death in rural Bangladesh. Eur J Neurol 2012;19(7):999-1006.

29. Boden-Albala B, Elkind MS, White H, Szumski A, Paik MC, Sacco RL. Dietary total fat intake and ischemic stroke risk: The Northern Manhattan Study. Neuroepidemiology 2009;32(4):296-301.

30. Lopez-Garcia E, Rodriguez-Artalejo F, Rexrode KM, Logroscino G, $\mathrm{Hu}$ FB, van Dam RM. Coffee consumption and risk of stroke in women. Circulation 2009;119(8):1116-23.

31. Larsson SC, Orsini N. Coffee consumption and risk of stroke: A dose-response meta-analysis of prospective studies. Am J Epidemiol 2011;174(9):993-1001.

32. Zhang R, Yan W, Song B, Hans S. Coffee consumption and risk of stroke: A meta-analysis of cohort studies. Cent Eur J Med 2012;7(3):310-6.

33. Dana MF, Daniel GN, Lacramioara PD. Circadian pattern of Ischemic stroke onset. HVM Bioflux 2014;6(3):132-9.

34. Geetha S, Sathisha A, Balaji V, Swetha ES. Analysis of drug utilization pattern among Hypertensive patients admitted to medical intensive care unit of a tertiary care hospital. WJPR 2015;4(3):1320-30.

35. White JR, Bettencourt-Silva JH, Potter JF, Loke YK, Myint PK. Changes in antiplatelet use prior to incident Ischaemic stroke over 7 years in a UK centre and the association with stroke subtype. Age Ageing 2013;42(5):594-8

36. Preethi PB, Abdul N, Shreya S, Sri Lakshmi G. Prescribing pattern of drugs in stroke patients admitted to a multi-specialty hospital, India. IAJPR 2014;4(2):1015-20.

37. Joseph TD, Robert L, Gary C, Gary R. Pharmacotherapy a Pathophysiological Approach. $7^{\text {th }}$ ed. New York, NY: McGraw-Hill; 2008. p. 373-83. 